Supplement of Atmos. Chem. Phys., 18, 11363-11374, 2018

https://doi.org/10.5194/acp-18-11363-2018-supplement

(C) Author(s) 2018. This work is distributed under

the Creative Commons Attribution 4.0 License.

(c) (1)

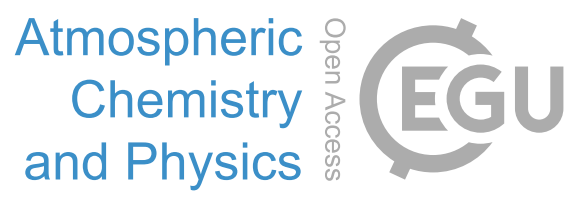

Supplement of

\title{
Primary and secondary organic aerosol from heated cooking oil emissions
}

Tengyu Liu et al.

Correspondence to: Chak K. Chan (chak.k.chan@cityu.edu.hk) and Xinming Wang (wangxm@gig.ac.cn)

The copyright of individual parts of the supplement might differ from the CC BY 4.0 License. 


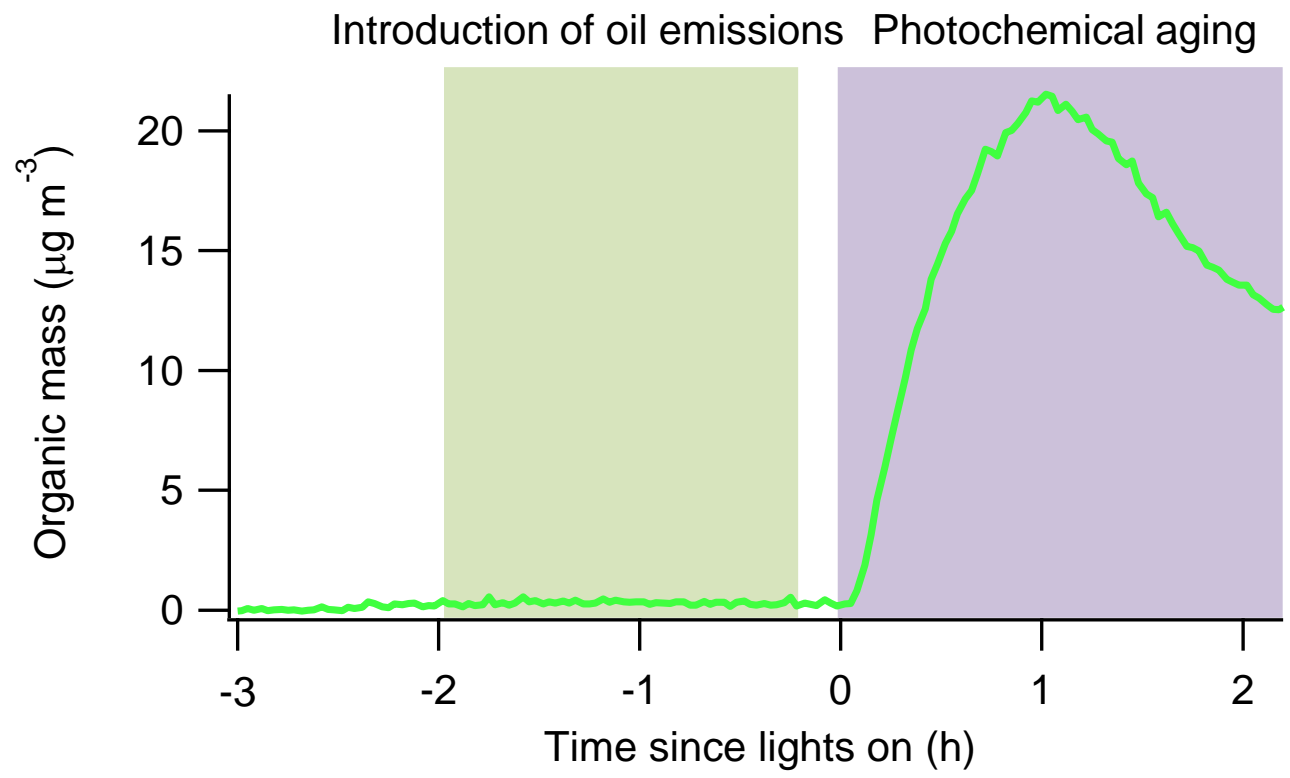

Fig. S1. Time series of organic mass concentration in a pure SOA experiment (sunflower oil). The emissions from heated sunflower oil were introduced from $t=-1.95 \mathrm{~h}$ to $\mathrm{t}=0.38 \mathrm{~h}$. The POA concentration was lower than $0.5 \mu \mathrm{g} \mathrm{m}^{-3}$ and thus was considered as negligible. 

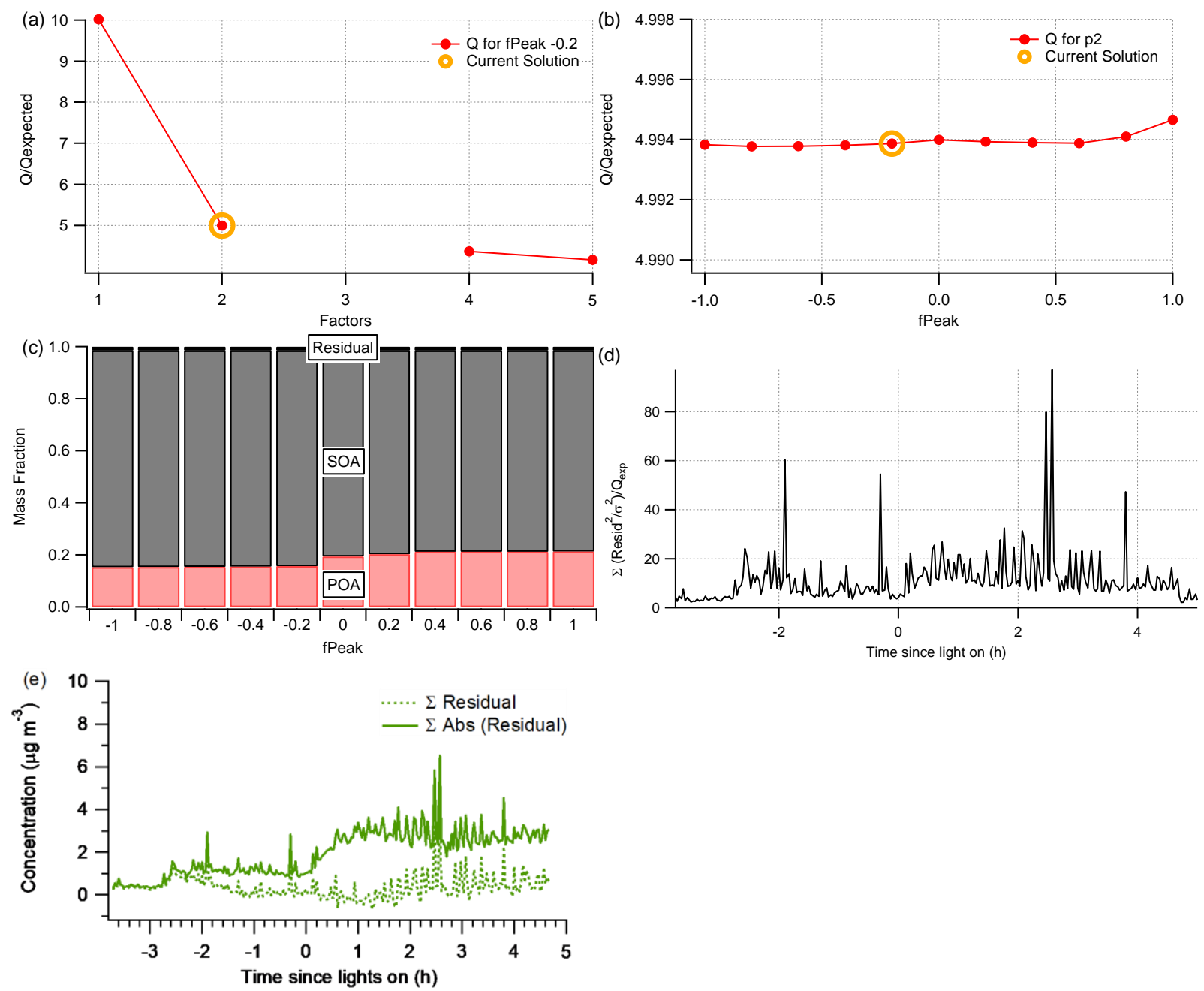

Fig. S2. Diagnostic plots of the PMF analysis for the palm oil experiment. The following plots are shown (a) $\mathrm{Q} / \mathrm{Q}_{\exp }$ vs number of factors; (b) $\mathrm{Q} / \mathrm{Q}_{\exp }$ vs. fPeak for the solution with optimal number of factors; (c) mass fraction of PMF factors vs. fPeak; (d) the time series of $\mathrm{Q} / \mathrm{Q}_{\mathrm{exp}}$; (e) the residual of PMF solutions. 

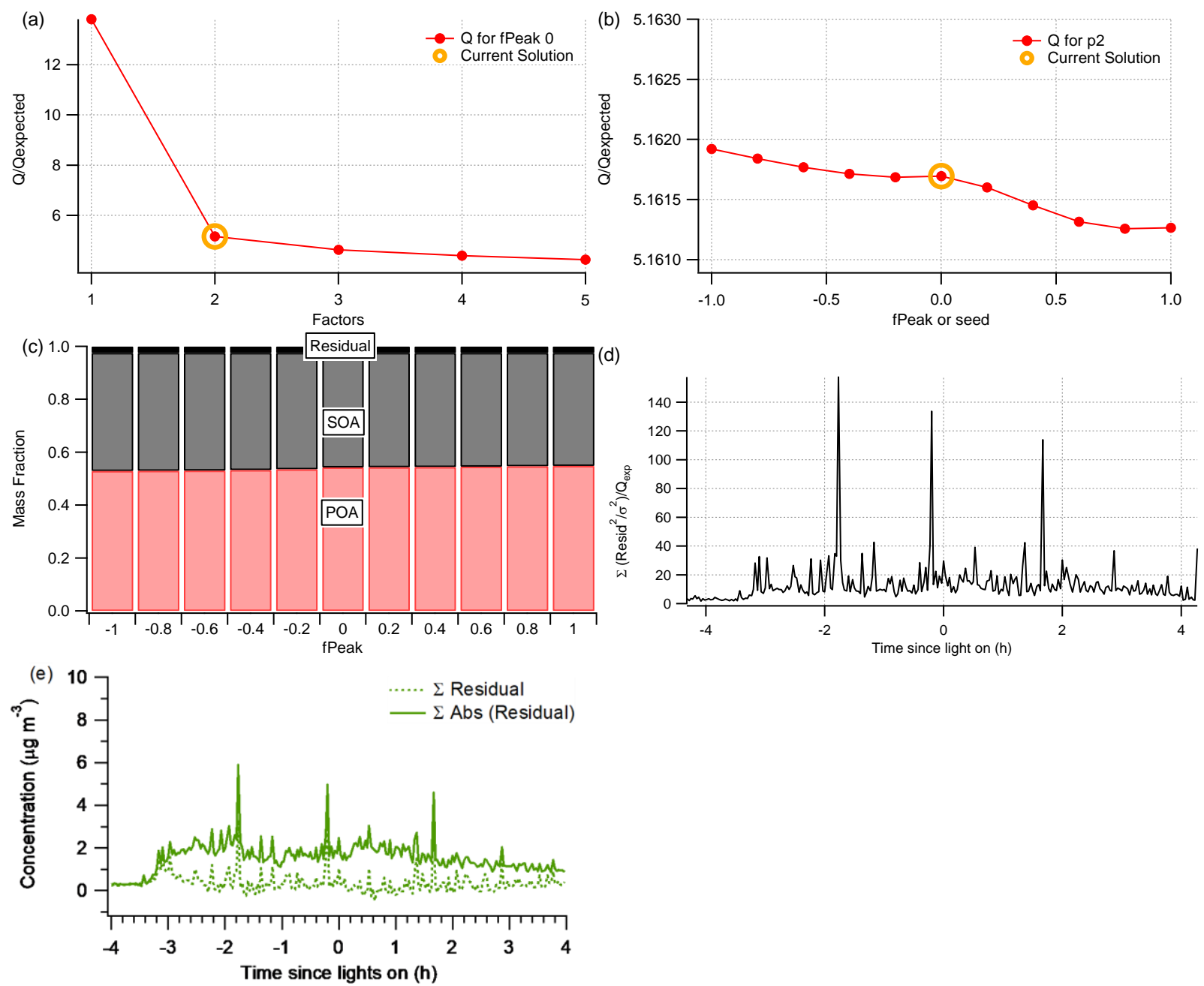

Fig. S3. Diagnostic plots of the PMF analysis for the olive oil experiment. The following plots are shown (a) $\mathrm{Q} / \mathrm{Q}_{\exp }$ vs number of factors; (b) $\mathrm{Q} / \mathrm{Q}_{\exp }$ vs. fPeak for the solution with optimal number of factors; (c) mass fraction of PMF factors vs. fPeak; (d) the time series of Q/Q $\mathrm{Q}_{\text {exp }}$; (e) the residual of PMF solutions. 

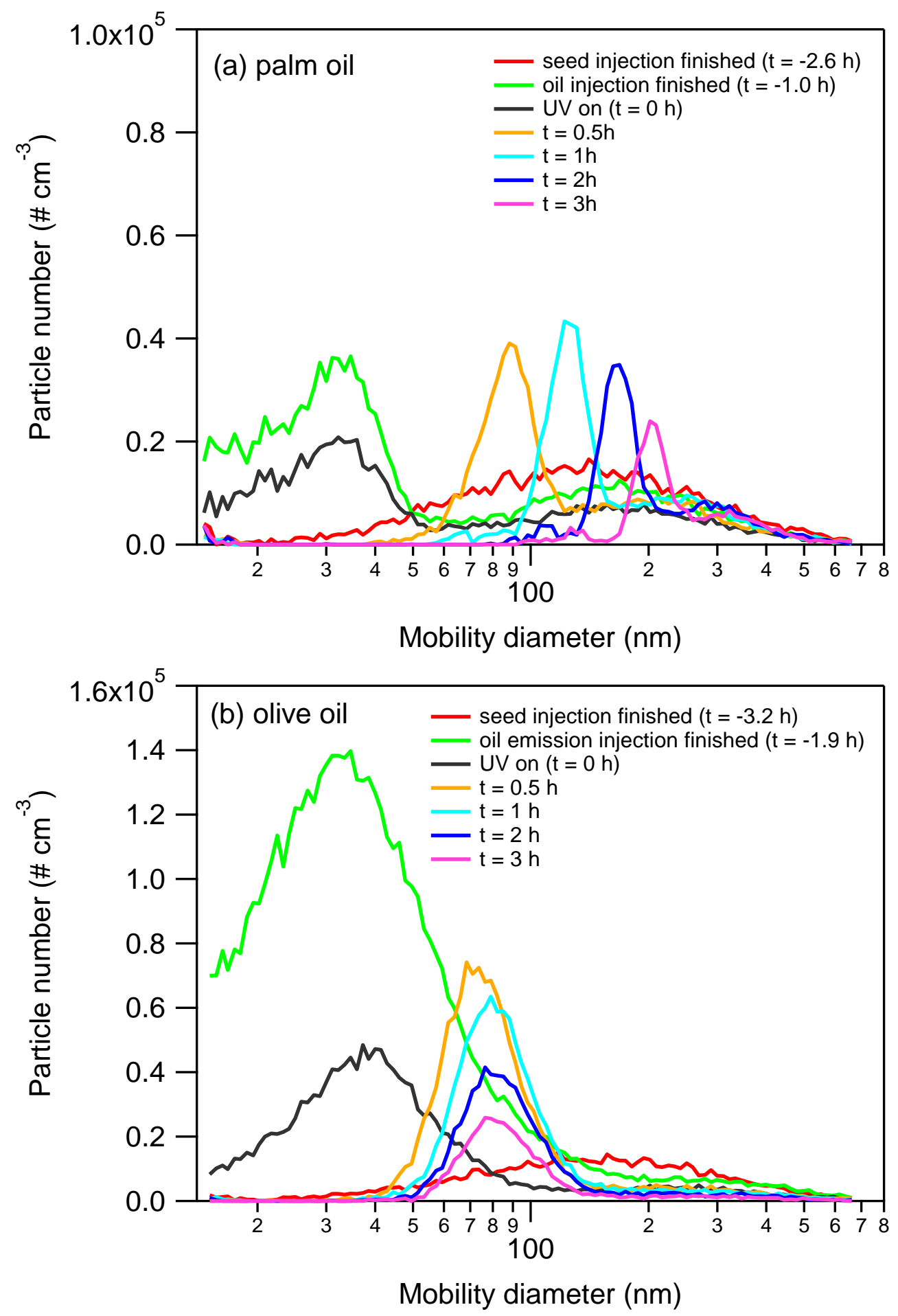

Fig. S4. Evolution of particle number size distribution for (a) palm and (b) olive oil experiments. 


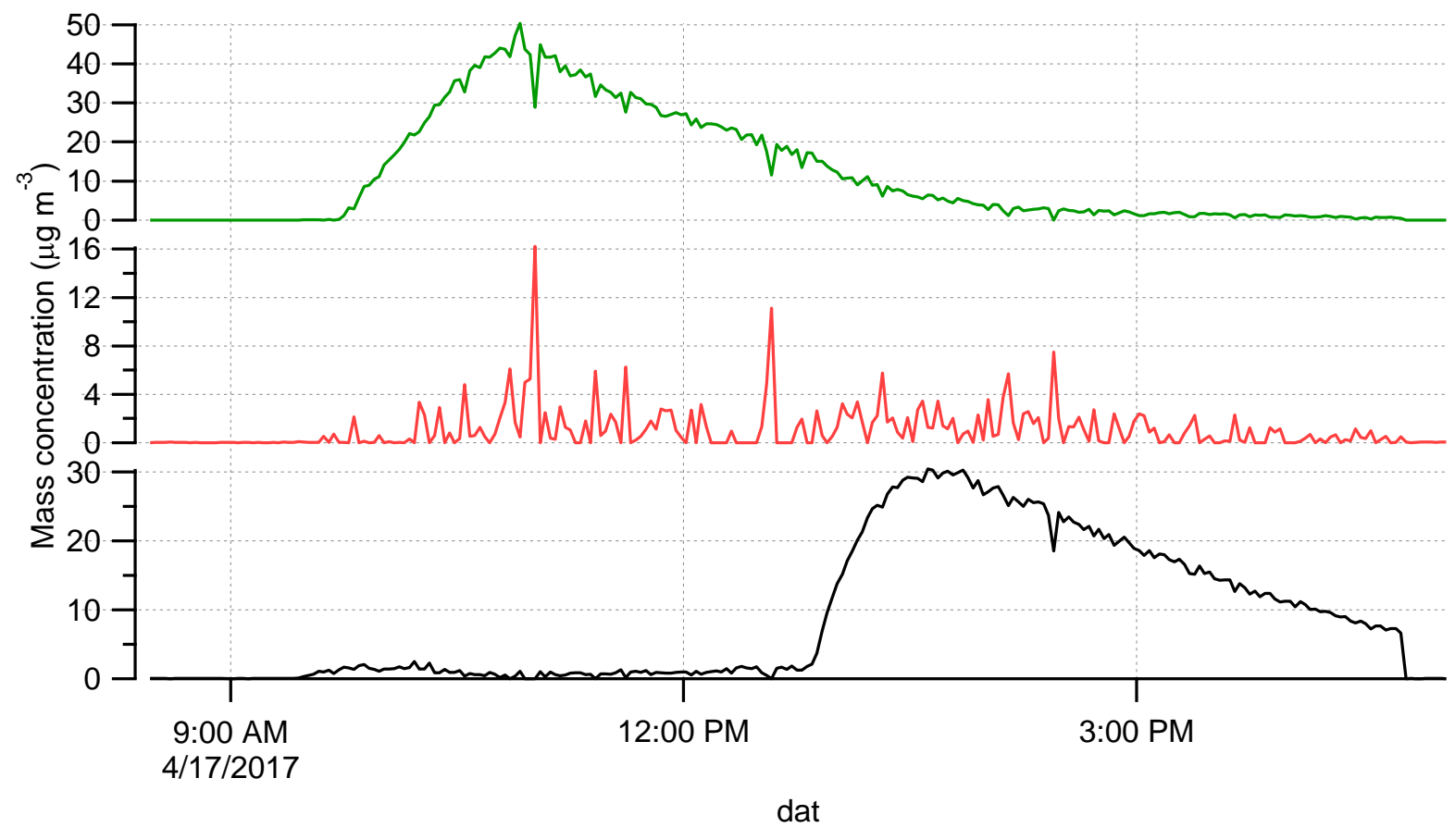

Fig. S5. Time series of the three factor solutions of PMF analysis with fPeak $=0$ for the olive oil experiment. 

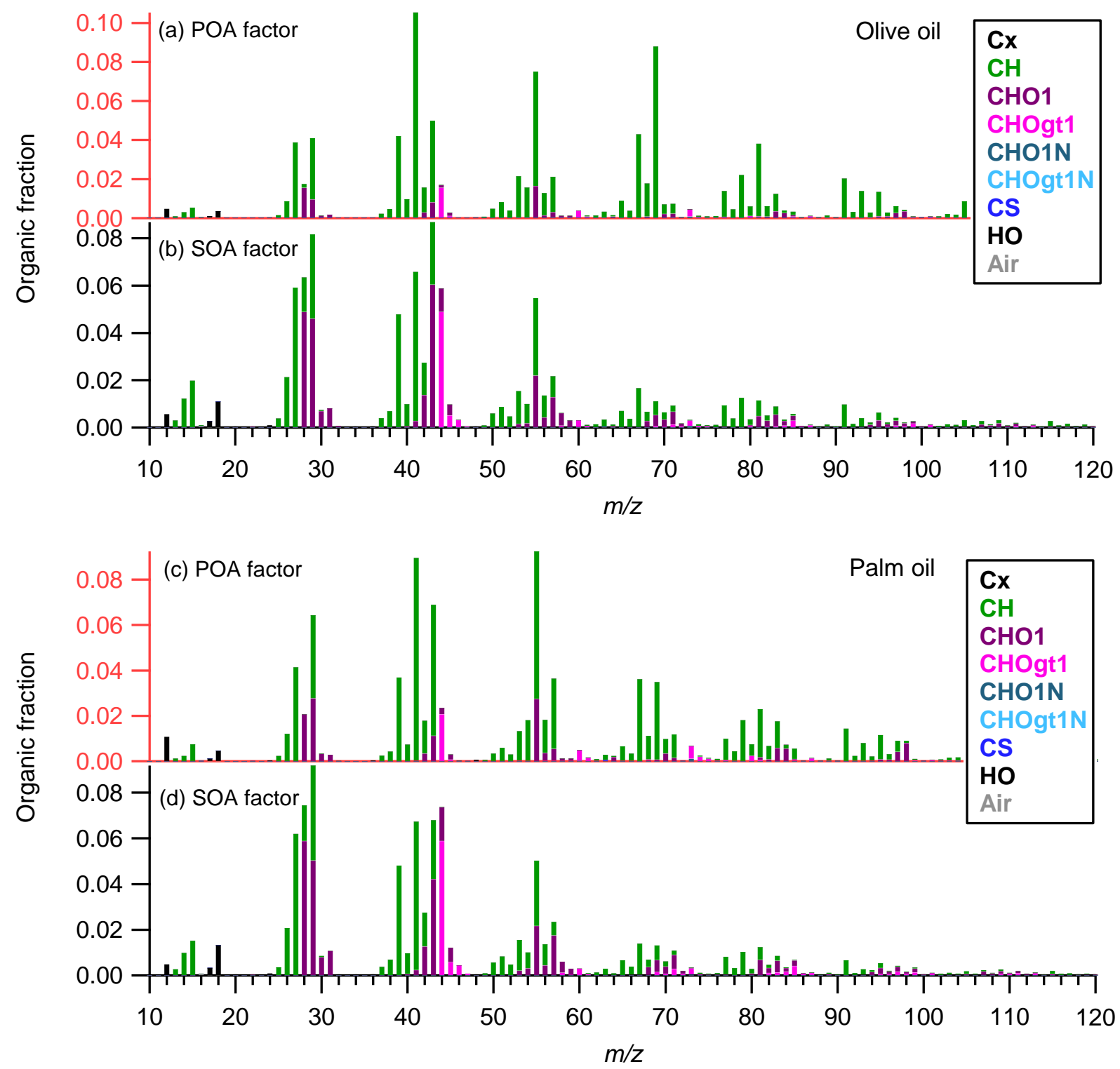

Fig. S6. High-resolution mass spectra of PMF-derived POA and SOA factors for the olive and palm oil. 


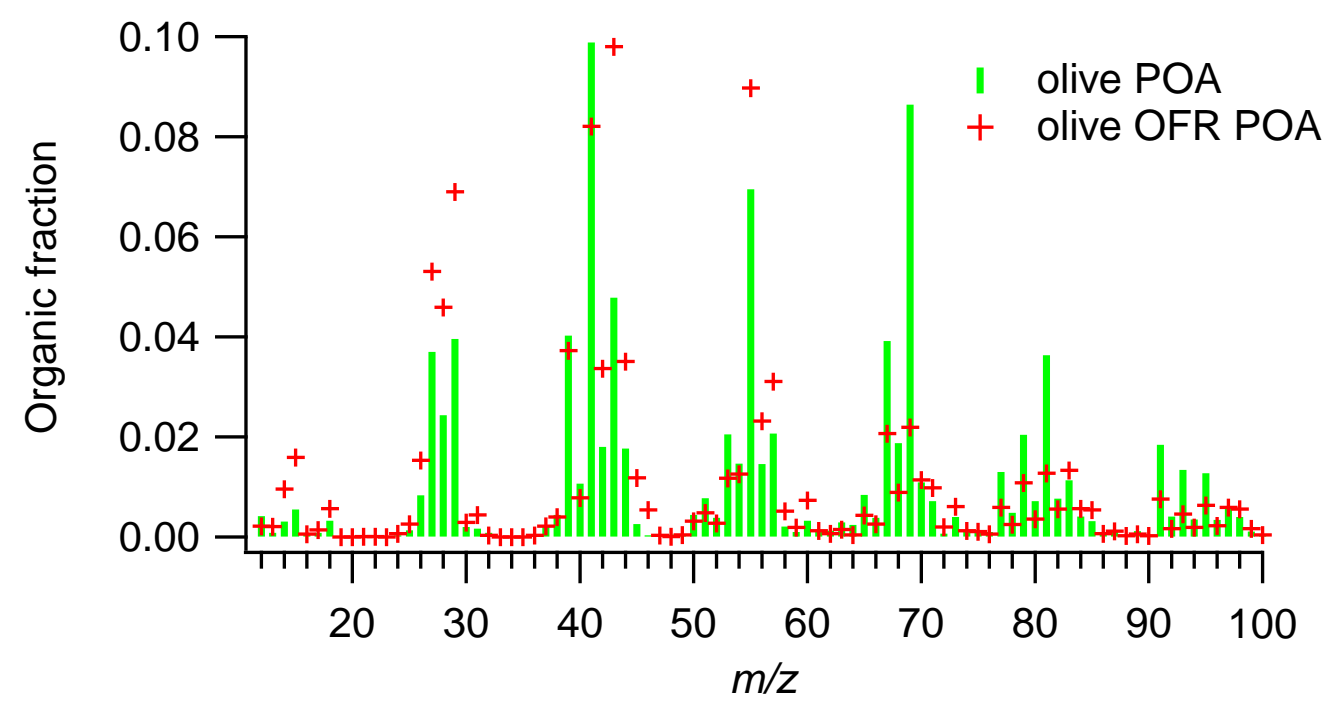

Fig. S7. Mass spectra of POA emissions in this study and POA measured in an oxidation flow reactor (Liu et al., 2017) for olive oil. 


\section{References}

Liu, T., Li, Z., Chan, M., and Chan, C. K.: Formation of secondary organic aerosols from gas-phase emissions of heated cooking oils, Atmos. Chem. Phys., 17, 7333-7344, https://doi.org/10.5194/acp-17-7333-2017, 2017. 